\title{
A comparative investigation of the metabolism of the herbicide glufosinate in cell cultures of transgenic glufosinate-resistant and non-transgenic oilseed rape (Brassica napus) and corn (Zea mays)
}

\author{
Monika RUHLAND ${ }^{1}$, Gabriele ENGELHARDT ${ }^{1, *}$ and Karlheinz PAWLIZKI ${ }^{2}$ \\ ${ }^{1}$ Bayerisches Landesamt für Gesundheit und Lebensmittelsicherheit, Außenstelle München, Menzinger Straße 54, 80638 München, \\ Germany \\ ${ }^{2}$ Bayerische Landesanstalt für Bodenkultur und Pflanzenbau, Menzinger Straße 54, 80638 München, Germany
}

To obtain information on differences between the metabolic pathways of the herbicide glufosinate (trade names: BASTA $^{\circledR}$, LIBERTY ${ }^{\circledR}$ ) in non-transgenic, glufosinate-sensitive plants and in transgenic, glufosinate-resistant plants, the metabolism of ${ }^{14} \mathrm{C}$-labeled glufosinate and its enantiomers L- and D-glufosinate was studied using cell cultures of oilseed rape and corn. Transformation of glufosinate in both sensitive and transgenic rape cells remained at a low rate of about $3-10 \%$ in contrast to corn cells, where $20 \%$ was transformed in sensitive and $43 \%$ in transgenic cells after 14 days of incubation, the rest remaining as unchanged glufosinate. In sensitive rape and corn cells the main metabolite was 4-methylphosphinico-2-oxo-butanoic acid (PPO) with 7.3 and $16.4 \%$, respectively, together with low amounts of 3-methylphosphinicopropionic acid (MPP), 4-methylphosphinico-2-hydroxybutanoic acid (MHB), 4-methylphosphinicobutanoic acid (MPB) and 2-methylphosphinicoacetic acid (MPA). An additional metabolite formed in transgenic cell cultures was 2acetamido-4-methylbutanoic acid (N-acetyl-L-glufosinate, NGA), which was formed at rates of $3.2 \%$ in rape and $16.1 \%$ in corn. A further minor metabolite, not yet identified, was detected in both cell types. The liberation of $0.2 \%{ }^{14} \mathrm{CO}_{2}$ indicates further metabolic steps prior to a limited mineralization in plant cell cultures. L-glufosinate was transformed into the same metabolites as the glufosinate racemate. D-glufosinate was not metabolized.

Key words: glufosinate, herbicide resistance, metabolism, phosphinothricin, transgenic plants, cell cultures.

Abbreviations: DGA: D-homoalanin-4-yl-(methyl)phosphinic acid; GA: glufosinate, D/L-homoalanin-4-yl(methyl)phosphinic acid; LGA: L-homoalanin-4-yl-(methyl)phosphinic acid; MHB: 4-methylphosphinico-2hydroxybutanoic acid; MPA: methylphosphinicoacetic acid; MPB: 4-methylphosphinicobutanoic acid; MPP: 3-methylphosphinicopropionic acid; NGA: N-acetyl-glufosinate; PPO: 4-methylphosphinico-2-oxo-butanoic acid

\section{INTRODUCTION}

The herbicide glufosinate (GA, D/L-homoalanin-4-yl(methyl)phosphinic acid), which is utilized as ammonium salt in commercial formulations, consists of a racemate of the D- and L-enantiomers (DGA, LGA). L-glufosinate is the active ingredient of the broadspectrum, non-selective herbicide BASTA $^{\circledR}$. It is a natural phytotoxin (phosphinothricin) and was shown to be a potent inhibitor of glutamine synthetase which controls ammonia assimilation in higher plants (Lea et al., 1984; Leason et al., 1982). Inhibition of the enzyme leads to toxic levels of ammonia and deficiency of glutamine, resulting in the death of the plant cells. With the aid of genetic engineering, herbicide tolerance of crop plants was achieved by transferring a resistance gene

\footnotetext{
* Corresponding author:

Tel.: (49) 89178002 14; fax: (49) 89178001 70; e-mail: gabriele.engelhardt@lfe.bayern.de
} 
(pat or bar gene) into previously susceptible plants. This new approach makes it possible to apply glufosinate post-emergence in the selective herbicide LIBERTY ${ }^{\circledR}$ in transgenic crops. LIBERTY ${ }^{\circledR}$ contains the same ingredients as BASTA ${ }^{\circledR}$.

Glufosinate-resistant plants express the phosphinothricin $\mathrm{N}$-acetyltransferase gene which confers resistance to glufosinate by $\mathrm{N}$-acetylation of glufosinate, thereby inactivating the molecule (Wohlleben et al., 1988). Since herbicide tolerance and post-emergence application may lead to an increase of herbicide uptake and therefore to the formation of higher or new hitherto unknown residues in tolerant crop plants, the metabolism and distribution of glufosinate in these plants should be studied in detail.

At present only few data on the metabolic behavior of glufosinate in plants have been published. Dröge et al. $(1992,1994)$ studied the metabolism of glufosinate in sterile transformed and untransformed alfalfa (Medicago sativa), tobacco (Nicotiana tabacum), carrot (Daucus carota), and found 4-methylphosphinico-2-oxobutanoic acid (PPO), 3-methylphosphinicopropionic acid (MPP) and 4-methylphosphinico-2-hydroxy-butanoic acid (MHB) in untransformed plants and additionally $\mathrm{N}$-acetyl-glufosinate in transformed plants as main metabolites. The D-enantiomer was found to be stable in these sterile plants. Recent studies of Jansen et al. (2000) on glufosinate metabolism in excised shoots and leaves of twenty plant species showed MPP to be the main metabolite in all species tested, together with low amounts of MHB in 14 species.

In cell cultures of unmodified corn (Zea mays (L.)), wheat (Triticum aestivum) and soybean (Glycine max.), Komoßa and Sandermann (1992) detected 4-methylphosphinico-butanoic acid (MPB), PPO, MPP and MHB. They also observed differences in the type of metabolites formed, depending on the plant species. Studies on the metabolism of glufosinate in cell cultures of genetically modified and unmodified cell cultures of sugarbeet (Beta vulgaris), carrot, purple foxglove (Digitalis purpurea) and thorn apple (Datura stramonium (L.)) were recently published by Müller et al. (1999, 2001). In transgenic sugarbeet $\mathrm{N}$-acetyl-glufosinate proved to be the main metabolite, together with traces of MPP and MHB, whilst in non-transgenic sugarbeet, carrot, purple foxglove and thorn apple, the herbicide was transformed to a limited extent to MPB and trace amounts of MHB.

In order to compare the metabolic pathways of glufosinate and its enantiomers in transgenic and nontransgenic plant cells, separate degradation studies with the different glufosinate-enantiomers were carried out using cell cultures from oilseed rape (Brassica napus (L.)) and corn (Z. mays). Sterile, heterotrophic cell cultures were used for the studies to exclude microbial influences on pesticide degradation and to detect and quantify all possible metabolites, which is very difficult to realize in studies with intact plants (Langebartels et al., 1986).

\section{RESULTS}

\section{Susceptibility of glufosinate-sensitive and glufosinate-resistant oilseed rape and corn cells to glufosinate and its enantiomers}

To examine the susceptibility of glufosinate-sensitive and -resistant plant cells to the different enantiomers, cell growth of suspension cultures was measured in the presence of increasing concentrations of glufosinate, LGA and DGA, respectively. Susceptibility depended both on the type of enantiomer and on the cells used. Whereas transformed oilseed rape and corn cells tolerated concentrations of $\geq 200 \mathrm{mg} . \mathrm{L}^{-1}$ of all enantiomers, sensitive oilseed rape cells tolerated concentrations of only $0.05 \mathrm{mg} . \mathrm{L}^{-1} \mathrm{LGA}$ and $0.1 \mathrm{mg} . \mathrm{L}^{-1}$ glufosinate, and sensitive oilseed corn cells tolerated concentrations of only $0.75 \mathrm{mg} . \mathrm{L}^{-1} \mathrm{LGA}$ and $1.25 \mathrm{mg} . \mathrm{L}^{-1}$ glufosinate. Both sensitive cell types, however, tolerated $\geq 10 \mathrm{mg} . \mathrm{L}^{-1}$ DGA. Growth retardation therefore seems to be based exclusively on the LGA content. On the basis of these results, for the metabolism studies, cells were incubated in the presence of $0.5 \mathrm{mg} . \mathrm{L}^{-1}$ glufosinate, LGA and DGA with one exception: $0.25 \mathrm{mg} . \mathrm{L}^{-1}$ LGA in untransformed oilseed rape. This slightly phytotoxic concentration was used in order to ensure the detectability of all potential metabolites.

\section{Distribution of total radioactivity after incubation with ${ }^{14} \mathrm{C}$-glufosinate}

Distribution of radioactivity of ${ }^{14} \mathrm{C}$-glufosinate between culture media and cell extracts was determined after 3 to 21 days of incubation. As shown in Table 1, the concentrations of radioactivity after 14 days were low in all cells, and amounted to between 13.5 and $18.3 \%$ of initial activity. The major portion (73-86\%) of radioactivity remained in the medium. No further accumulation in the cell extract was obtained in sensitive oilseed rape between 7 and 21 days, or in resistant oilseed rape between 14 and 21 days. In contrast, about $18 \%$ was detected after 14 days in resistant and sensitive corn cell extract, where the contents increased to $25.9 \%$ and $20 \%$, respectively, after 21 days. 
Table 1. Distribution of ${ }^{14} \mathrm{C}$-activity in culture media and aqueous cell extracts of glufosinate-resistant and glufosinate-sensitive oilseed rape and corn cell suspensions at different times after incubation with ${ }^{14} \mathrm{C}$-glufosinate, as percent of initial radioactivity.

\begin{tabular}{|c|c|c|c|c|c|c|c|c|c|c|c|c|}
\hline \multirow{3}{*}{$\begin{array}{l}\text { Time } \\
\text { (days) }\end{array}$} & \multicolumn{6}{|c|}{ Rape } & \multicolumn{6}{|c|}{ Corn } \\
\hline & \multicolumn{3}{|c|}{ GA-sensitive } & \multicolumn{3}{|c|}{ GA-resistant } & \multicolumn{3}{|c|}{ GA-sensitive } & \multicolumn{3}{|c|}{ GA-resistant } \\
\hline & $\begin{array}{c}\text { Culture } \\
\text { media }\end{array}$ & Cells & Total & $\begin{array}{c}\text { Culture } \\
\text { media }\end{array}$ & Cells & Total & $\begin{array}{c}\text { Culture } \\
\text { media }\end{array}$ & Cells & Total & $\begin{array}{c}\text { Culture } \\
\text { media }\end{array}$ & Cells & Total \\
\hline 3 & 96.8 & 2.9 & 99.7 & 96.3 & 2.3 & 98.6 & 90.0 & 9.1 & 99.1 & 95.3 & 7.8 & 103.1 \\
\hline 7 & 85.3 & 13.0 & 98.3 & 91.2 & 7.0 & 98.2 & 85.5 & 12.8 & 98.3 & 88.6 & 15.4 & 104.0 \\
\hline 14 & 86.4 & 13.5 & 99.9 & 85.8 & 14.3 & 100.1 & 73.1 & 18.3 & 91.4 & 81.8 & 17.7 & 99.5 \\
\hline 21 & n.d. & n.d. & n.d. & 84.3 & 13.3 & 97.6 & 74.8 & 20.0 & 94.8 & 78.2 & 25.9 & 104.1 \\
\hline
\end{tabular}

Table 2. Amounts of ${ }^{14} \mathrm{C}$-glufosinate and metabolites in cell cultures of sensitive and transgenic, glufosinate-resistant oilseed rape after 3 to 21 days of incubation (sum of residues in cell extracts and culture media in $\%$ of added radioactivity).

\begin{tabular}{lccccccccc}
\hline \hline & $\begin{array}{c}\text { Time } \\
\text { (days) }\end{array}$ & GA & MPB & MPP & MHB & NGA & MPA & PPO & $\begin{array}{c}\text { Total } \\
\text { Metabolites }\end{array}$ \\
\hline Sensitive rape & 3 & 97.1 & 0.17 & 0.24 & - & - & 0.09 & 0.63 & 1.13 \\
& 7 & 93.4 & 0.38 & 0.33 & 0.45 & - & 0.23 & 1.80 & 3.19 \\
& 14 & 84.2 & 0.47 & 0.86 & 0.77 & - & 0.18 & 7.30 & 9.58 \\
\hline Transgenic rape & 3 & 96.1 & - & - & 0.13 & 1.27 & 0.06 & 0.39 & 1.85 \\
& 7 & 88.8 & 0.27 & 0.05 & 0.08 & 3.96 & 0.1 & - & 4.46 \\
& 14 & 90.0 & 0.18 & 0.08 & 0.05 & 3.20 & 0.08 & 0.15 & 3.74 \\
& 21 & 88.0 & 0.05 & 0.31 & 0.62 & 1.99 & 0.16 & - & 3.13 \\
\hline
\end{tabular}

\section{Properties of ${ }^{14} \mathrm{C}$-labeled residues}

In all cell cultures, after an incubation period of 14 days about $96 \%$ of ${ }^{14} \mathrm{C}$-labeled residues was extractable with water and not more than $0.5 \%$ could be detected in the organic phase of cell extracts. Not more than $0.2 \%$ of the added radioactivity was released as ${ }^{14} \mathrm{CO}_{2}$. Since the glufosinate used in our experiments was labeled at $\mathrm{C} 3$ and $\mathrm{C} 4$, the detection of ${ }^{14} \mathrm{CO}_{2}$ indicates a possible mineralization of the herbicide. In addition, low amounts of radioactivity were also detected in non-extractable residues ranging from $0.5 \%$ to $1.3 \%$ of the initial radioactivity added. Therefore further analyses focused only on the aqueous phase obtained from culture media and cells.

\section{Time course of ${ }^{14} \mathrm{C}$-glufosinate transformation and metabolite formation}

As shown in Tables 2 and 3, about 84 to $88 \%$ of the applied radioactivity remained unchanged in sensitive and transgenic oilseed rape cells, respectively, and about $70 \%$ in both types of corn cells. In both types of oilseed rape cells the metabolic rates calculated from the relative percentages of individual metabolites detected in cell extracts and media were low, and relative to initial total radioactivity increased from $1.1 \%$ to $9.6 \%$ in sensitive and from $1.9 \%$ to $3.7 \%$ in transgenic, resistant oilseed rape cells at day 14. By contrast, in corn cells the metabolic rates were considerably higher, and had increased from 4.1 to $18.5 \%$ in sensitive, and from 28 to $42.8 \%$ in transformed cultures by day 14 .

The amounts of all other detected metabolites increased continuously from 3 to 21 days of incubation without intermediate accumulation of individual metabolites. In sensitive cells the main metabolite after 14 days of incubation was PPO with $7.3 \%$ of the added radioactivity in oilseed rape (Tab. 2) and $15.8 \%$ in corn (Tab. 3). The concentrations of 4-methylphosphinico-2hydroxybutanoic acid (MHB), 4-methylphosphinicobutanoic acid (MPB), 3-methylphosphinico propionic acid (MPP) and 2-methylphosphinicoacetic acid (MPA) 
Table 3. Amounts of ${ }^{14} \mathrm{C}$-glufosinate and metabolites in cell cultures of sensitive and transgenic, glufosinate-resistant corn after 3 to 21 days of incubation (sum of residues in cell extracts and culture media in \% of added radioactivity).

\begin{tabular}{lccccccccc}
\hline \hline & $\begin{array}{c}\text { Time } \\
\text { (days) }\end{array}$ & GA & MPB & MPP & MHB & NGA & MPA & PPO & $\begin{array}{c}\text { Total } \\
\text { metabolites }\end{array}$ \\
\hline Sensitive corn & 3 & 93.6 & 0.11 & - & 0.42 & - & - & 3.6 & 4.13 \\
& 7 & 85.5 & 0.22 & 0.012 & 1.11 & - & - & 11.0 & 12.3 \\
& 14 & 68.7 & 0.25 & 0.18 & 2.23 & - & traces & 15.8 & 18.5 \\
& 21 & 71.1 & 0.33 & 0.2 & 2.52 & - & traces & 16.4 & 19.5 \\
\hline Transgenic corn & 3 & 76.1 & 0.11 & 2.33 & 0.38 & 6.82 & 0.07 & 19.1 & 28.8 \\
& 7 & 60.2 & 0.48 & 2.57 & 0.93 & 14.3 & 0.14 & 23.1 & 36.6 \\
& 14 & 55.3 & 1.38 & 2.2 & 1.53 & 16.1 & 0.33 & 21.3 & 42.8 \\
& 21 & 69.4 & 1.49 & 1.99 & 1.4 & 20.3 & 0.52 & 3.25 & 29.0 \\
\hline
\end{tabular}

remained very low $(<10 \%$ of total metabolites recovered), with only a slight increase during incubation. NGA was not detected in sensitive cultures.

In contrast, the main metabolite in transgenic oilseed rape cells was NGA, which reached $3.2 \%$ of the added radioactivity, whereas PPO was detected in transgenic oilseed rape cultures only in very low amounts. In transgenic corn cells, however, $16 \%$ of the added radioactivity were transformed to NGA in addition to $21 \%$ of PPO as main metabolite after 14 days (Tabs. 2 and 3 ).

More than $95 \%$ of the PPO was usually found in the culture media, less than $5 \%$ in the cell extracts. The amounts of MHB, MPB, MPP and MPA detected were each below $2.6 \%$. Furthermore, one not yet identified compound was detected in very low amounts in some samples of both sensitive and resistant cell cultures. Due to these low amounts and the lack of an authentic reference substance it could not be identified by cochromatography.

\section{Comparison of metabolites of ${ }^{14} \mathrm{C}$-glufosinate and its enantiomers}

Since the commercially available herbicides LIBERTY ${ }^{\circledR}$ and BASTA ${ }^{\circledR}$ contain the racemic glufosinate, the metabolic behavior of each enantiomer was tested separately and compared with that of glufosinate. An incubation period of 14 days was applied, which the experiments with glufosinate had shown to be suitable. When DGA was applied, in all cell types the amounts of radioactivity within cells were only $3-7 \%$, whereas with
LGA the amounts of radioactivity within cells were about 50\% in transgenic corn and $20 \%$ in all other cell types after a 14-day incubation period. These results indicate that LGA is primarily taken up and metabolized from the racemic mixture of glufosinate by all cultures used.

The comparison of the residues formed from the different glufosinate enantiomers (Tabs. 4 and 5) shows that DGA is not transformed, and LGA forms the same metabolites as glufosinate in both oilseed rape and corn cells. This means that only the L-enantiomer of the herbicides BASTA ${ }^{\circledR}$ and LIBERTY ${ }^{\circledR}$ is transformed, but not the D-enantiomer.

Not only the enantiomeric form of the herbicide but the type of cells also had a strong influence on the metabolism of LGA and glufosinate. NGA was detected only in transgenic, glufosinate-resistant cells as main metabolite with 3 to $7 \%$ of the added radioactivity in oilseed rape (Tab. 4) and 16 to $52 \%$ in corn (Tab. 5). This metabolite was not formed in sensitive cells. All metabolites detected in sensitive cultures were also formed by transgenic cells. PPO, the main metabolite of glufosinate and LGA in sensitive oilseed rape (Tab. 4) and corn cell cultures (Tab. 5 ) - with about 2.5 and $7 \%$ in rape and with 16 and $44 \%$ in corn, respectively - could be detected in transgenic rape cells only in amounts below $0.15 \%$, but in transgenic corn cells in amounts up to $22 \%$.

On the basis of these results the degradation scheme shown in Figure 1 is proposed for the metabolism of L-glufosinate in transgenic, glufosinate-resistant and non-transgenic, glufosinate-sensitive oilseed rape and corn cells. 
Table 4. Comparison of the residues of LGA and DGA with glufosinate (GA) in sensitive and transgenic, glufosinate-resistant oilseed rape cells after an incubation period of 14 days (sum of residues in cell extracts and culture media in $\%$ of added radioactivity).

\begin{tabular}{ccccccccc}
\hline \hline & GA & MPB & MPP & MHB & NGA & MPA & PPO & Total \\
\hline Sensitive rape & & & & & & & & \\
GA & 84.2 & 0.47 & 0.86 & 0.8 & - & 0.18 & 7.3 & 93.8 \\
LGA & 73.6 & 0.25 & 3.0 & 0.6 & - & 0.5 & 2.5 & 80.5 \\
DGA & 90.7 & - & - & - & - & - & - & 90.7 \\
\hline Transgenic rape & & & & & & & & \\
GA & 90.0 & 0.18 & 0.08 & 0.05 & 3.2 & 0.08 & 0.15 & 93.7 \\
LGA & 75.1 & 0.02 & 0.44 & 1.2 & 6.8 & 0.43 & 0.14 & 84.1 \\
DGA & 96.0 & - & - & - & - & - & - & 96.0 \\
\hline
\end{tabular}

Table 5. Comparison of the residues of LGA and DGA with glufosinate (GA) in sensitive and transgenic, glufosinate-resistant corn cells after an incubation period of 14 days (sum of residues in cell extracts and culture media in \% of added radioactivity).

\begin{tabular}{ccccccccc}
\hline \hline & GA & MPB & MPP & MHB & NGA & MPA & PPO & Total \\
\hline Sensitive corn & & & & & & & & \\
GA & 68.7 & 0.25 & 0.18 & 2.2 & - & 0.7 & 15.8 & 87.8 \\
LGA & 38.4 & 0.31 & 4.9 & 1.2 & - & 0.4 & 43.5 & 88.7 \\
DGA & 79.0 & - & - & - & - & - & - & 79.0 \\
\hline Transgenic corn & & & & & & & & \\
GA & 55.3 & 1.4 & 2.2 & 1.5 & 16.1 & 0.33 & 21.3 & 98.1 \\
LGA & 24.5 & 3.3 & 1.6 & 6.5 & 52.5 & 0.7 & 6.3 & 95.4 \\
DGA & 95.0 & - & - & - & 1.5 & - & 0.21 & 96.7 \\
\hline
\end{tabular}

\section{DISCUSSION}

The aim of the present study was to determine whether the metabolism of glufosinate and its L- and D-enantiomers follows different pathways in transgenic and non-transgenic crop plants and whether NGA and DGA are stable in transgenic plants or transformed to unknown metabolites. Cell cultures have been accepted for metabolic studies in plants as an appropriate test system, providing an overall picture of the principal metabolic capability of the plant as a whole. For this reason, the metabolism of all glufosinate enantiomers was studied both in transgenic and non-transgenic cell cultures of oilseed rape and corn.

The results obtained show that the metabolic rates of glufosinate were low in cell cultures of sensitive and transgenic oilseed rape (4-10\%), and reached $20 \%$ in sensitive and $43 \%$ in transgenic corn. The low transformation rates are presumably caused by the low herbicide concentrations in the cells, ranging from $14 \%$ to $18 \%$ of the applied radioactivity. No non-polar, solvent extractable metabolites were formed and only very low amounts of non-extractable residues $(<1.5 \%)$ and ${ }^{14} \mathrm{C}$-labeled $\mathrm{CO}_{2}(<0.2 \%)$ could be detected.

In sensitive plant cells, glufosinate and LGA were transformed to a minor extent to PPO, MPP, MHB, MPB and MPA. Except for MPA, these metabolites have already been described in the literature (Dröge et al., 1992; Dröge-Laser et al., 1994; Jansen et al., 2000; Komoßa and Sandermann, 1992; Müller et al., 1999; Müller et al., 2001). As shown by these studies, the first step in the metabolic pathway of LGA in sensitive plants is degradation of the amino group by deamination to the corresponding alpha-oxo-carboxylic acid (PPO). This 

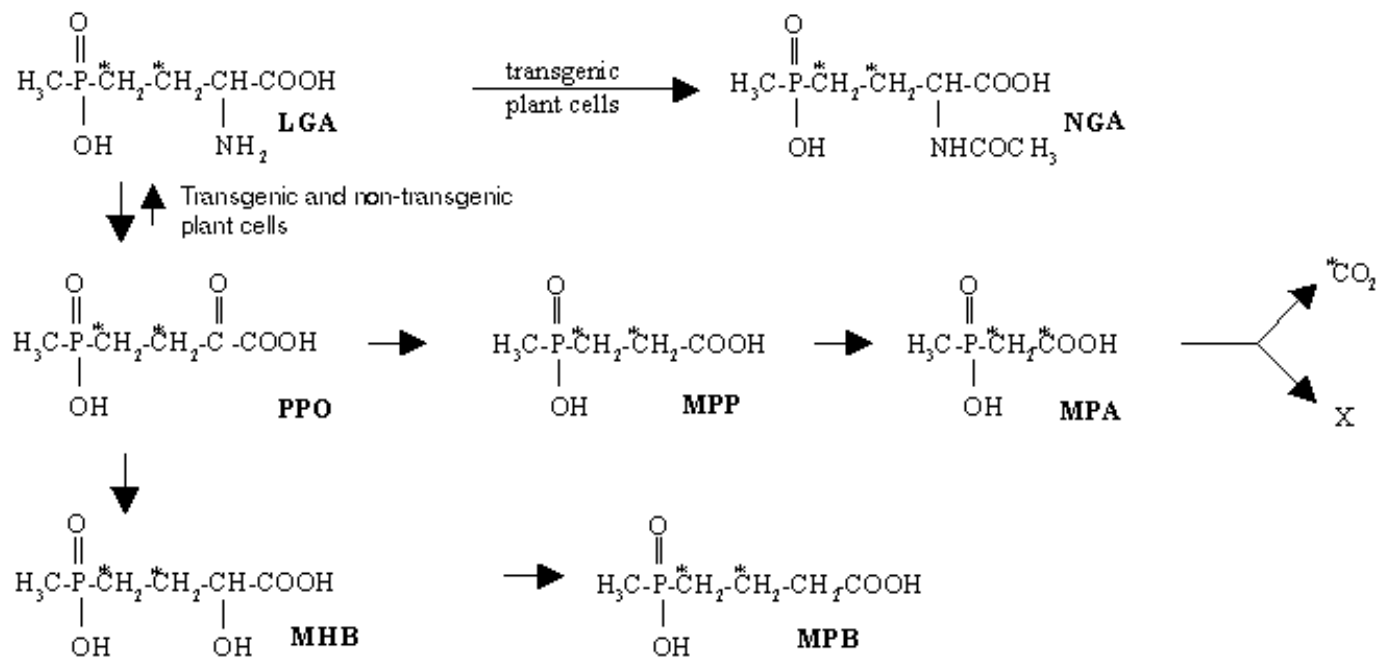

Figure 1. Degradation scheme proposed for the metabolism of L-glufosinate in cell cultures of sensitive and transgenic, glufosinate-resistant oilseed rape and corn $\left(* \mathrm{C}={ }^{14} \mathrm{C}\right.$-labeled, $\mathrm{X}=$ unknown metabolite).

intermediate is metabolized further by oxidative decarboxylation to MPP or reduction to MHB. PPO is described to be unstable and easily transformed to glufosinate and/or MPP (Dröge et al., 1992; Dröge-Laser et al., 1994), which might account for the differing contents of PPO within the experiments. Further breakdown of the molecule proceeds via $\alpha$ - and $\beta$ oxidation analogous to natural fatty acids. Up to now the decarboxylation of MPP to MPA has been described only for metabolism of the herbicide in soil (Behrendt et al., 1990; Zumdick et al., 1998).

The detection of MPA in cell cultures of oilseed rape and corn indicates that further degradation of MPP is also possible in plant metabolism. As shown by the liberation of ${ }^{14} \mathrm{CO}_{2}$ from the radiolabeled $\mathrm{C} 3$ and $\mathrm{C} 4$, partial mineralization of glufosinate via MPA and the hitherto unknown metabolite cannot be excluded.

As opposed to the results obtained by Komoßa and Sandermann (1992) and Müller et al. (2001), PPO was detectable in our study mainly in corn cells in amounts of up to $21 \%$ of the total radioactivity added. More than $95 \%$ of these PPO residues were generally found in the culture media and only up to $5 \%$ in cell extracts. The detection of PPO can presumably be accounted for by differences in the clean-up procedures applied. Whereas Müller et al. (2001) concentrated the culture media in vасио, we used freeze drying. Under these conditions the unstable metabolite PPO presumably was not transformed further. The decrease of the concentrations of PPO and total metabolites from day 14 to day 21 in transgenic corn (Tab. 3) corresponds approximately to the increase of glufosinate and NGA at day 21. This behavior is presumably caused by the instability of PPO leading to glufosinate and NGA (Dröge-Laser et al., 1994).

NGA was formed only in transgenic oilseed rape and corn cells. It was the main metabolite in transgenic oilseed rape, whereas in transgenic corn large amounts of NGA were formed together with $\mathrm{PPO}$ as main metabolite. In addition, traces of MPB, MPP, MHB and MPA were also formed in all transgenic plant cells, which indicates that, apart from acetylation, the same metabolic reactions are involved as in sensitive plants. Comparison of the results obtained for both sensitive and transgenic plant cells demonstrates that NGA is only formed in transgenic but not in sensitive plant cells. The deamination of glufosinate as the other potential way of deactivating is not rapid enough to avoid phytotoxicity in plants, whereas acetylation has to be rapid to ensure the sudden loss of herbicidal activity. NGA is commonly considered to be stable in transgenic plant cells (DrögeLaser et al., 1994; Müller et al., 1999).

The remarkable differences of total metabolites between sensitive and transgenic oilseed rape (Tab. 2) are probably due to the amounts of glufosinate applied, i.e. $0.25 \mathrm{mg} . \mathrm{L}^{-1}$ in sensitive and $0.5 \mathrm{mg} . \mathrm{L}^{-1}$ in transgenic rape. These data indicate that a relatively low amount of the high glufosinate dose is metabolized in transgenic oilseed rape (Tab. 2) and a relatively large portion of the low glufosinate dose in sensitive oilseed rape. 
Degradation of glufosinate was influenced not only by the cell type but also by the enantiomeric form of glufosinate applied. All metabolites were formed from LGA but not from the D-enantiomer. As already concluded by Dröge et al. (1992) from the metabolism of glufosinate in sterile transgenic plants, DGA seems to be stable in plant metabolism under sterile conditions. The separate use of LGA and DGA confirms the metabolic stability of DGA in both sensitive and transgenic oilseed rape and corn cells. According to the results obtained from this study, glufosinate, NGA, PPO and DGA have to be regarded as major residues in transgenic plant cells.

Although the enzymatic reactions of plant metabolism are generally represented in cell cultures, the results are not directly transferable to intact plants, since the degradation of glufosinate in crops is additionally influenced by microorganisms and weather conditions. Moreover, studies with cell cultures do not yield information on the uptake and distribution of glufosinate residues in different plant parts. For this reason, metabolism studies with ${ }^{14} \mathrm{C}$-glufosinate and its L- and D-enantiomers have since been performed with transgenic oilseed rape and corn plants under outdoor conditions and will be published in the near future.

\section{MATERIALS AND METHODS}

\section{Chemicals}

Non-labeled D/L-homoalanin-4-yl-(methyl)phosphinic acid (glufosinate, GA), D-homoalanin-4-yl-(methyl) phosphinic acid (DGA) and L-homoalanin-4-yl-(methyl) phosphinic acid (LGA) were provided by Aventis CropScience GmbH (Frankfurt/Main, Germany), as well as the following ${ }^{14} \mathrm{C}$-radiolabeled compounds: $\left[3,4-{ }^{14} \mathrm{C}\right]-\mathrm{D} /$ L-homoalanin-4-yl-(methyl)phosphinic acid (glufosina-

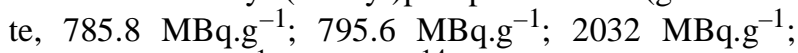
$\left.4860 \quad \mathrm{MBq} \cdot \mathrm{g}^{-1}\right), \quad\left[3,4-{ }^{14} \mathrm{C}\right]-(\mathrm{D})$-homoalanin-4-yl(methyl)phosphinic acid (DGA, $2081 \mathrm{MBq}^{-1}$ ), [3,4$\left.{ }^{14} \mathrm{C}\right]$-ammonium-(L)-homoalanin-4-yl-(methyl)phosphinic acid (LGA, 1239 MBq.g ${ }^{-1} ; 4637 \mathrm{MBq}^{-1}{ }^{-1}$; $\left.1589 \mathrm{MBq} \cdot \mathrm{g}^{-1}\right), \quad\left[3,4-{ }^{14} \mathrm{C}\right]$-disodium-L-2-acetamido-4methylphosphinatobutyrate (N-acetyl-glufosinate, NGA, $\left.4071 \mathrm{MBq} \cdot \mathrm{g}^{-1}\right),\left[2-{ }^{14} \mathrm{C}\right]-2$-methylphosphinicoacetic acid (MPA, 905.1 MBq.g ${ }^{-1}$ ), [2,3- $\left.{ }^{14} \mathrm{C}\right]-3$-methylphosphinicopropionic acid (MPP, $2752 \mathrm{MBq}^{-1}{ }^{-1}$ ), $\left[3,4-{ }^{14} \mathrm{C}\right]-4-$ methylphosphinicobutanoic acid (MPB, $334.7 \mathrm{MBq}^{-1}$ ), [3,4- $\left.{ }^{14} \mathrm{C}\right]$-disodium (D/L)-2-hydroxy-4-(methyl)phosphinicobutyrate (MHB, $\left.3.392 \mathrm{MBq} \cdot \mathrm{g}^{-1}\right),\left[3,4-{ }^{14} \mathrm{C}\right]-$ 4-methylphosphinico-2-oxo-butanoic acid (PPO, 141 MBq. $\left.{ }^{-1}\right)$.

\section{Preparation of transgenic plant cell cultures and culture conditions}

For the preparation of sterile callus cultures, transgenic L-glufosinate-resistant oilseed rape seeds and corn kernels with 15-day-old embryos were kindly provided by Aventis CropScience $\mathrm{GmbH}$, Frankfurt. Genetically unmodified (glufosinate-sensitive) oilseed rape calli were donated by BASF AG, Ludwigshafen. Sensitive corn callus cultures (Black Mexican Sweet) were established in our laboratory. To establish glufosinateresistant oilseed rape callus cultures, seeds were sterilized using $10 \%$ sodium hypochlorite for 20 minutes and washed with sterile water. For shoot growth they were incubated on Murashige and Skoog basal salt mixture (Murashige and Skoog, 1962) with addition of $0.04 \mathrm{mg} . \mathrm{L}^{-1}$ indole-3-acetic acid, $0.2 \mu \mathrm{g} . \mathrm{L}^{-1}$ kinetin, 5 mg.. $\mathrm{L}^{-1}$ 2,4-dichlorophenoxyacetic acid, 30 g.. $\mathrm{L}^{-1}$ saccharose, $1 \mathrm{ml} . \mathrm{L}^{-1}$ Gamborg's vitamin solution (Gamborg et al., 1968) and 10 g.L $\mathrm{L}^{-1}$ agar. Pieces of sterile shoots were cut, transferred on medium and cultivated until callus formation. Oilseed rape callus was removed and further cultivated on a modified Murashige and Skoog medium (Murashige and Skoog, 1962) with a reduced concentration of 2,4-dichlorophenoxyacetic acid of $1 \mathrm{mg} \cdot \mathrm{L}^{-1}$.

L-glufosinate-resistant corn callus was obtained from 15-day-old corn embryos. Corn grains were separated from the cobs, sterilized with $3 \%$ sodium hypochlorite for 15 minutes and washed with sterile water. The embryos were separated from the corn under sterile conditions, and cultivated on induction medium for embryo culture with $9 \%$ saccharose, and the following

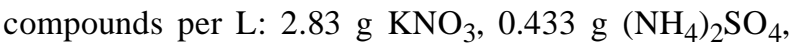
$0.166 \mathrm{~g} \mathrm{CaCl}_{2} 2 \mathrm{H}_{2} \mathrm{O}, 0.25 \mathrm{~g} \mathrm{MgSO}_{4} 7 \mathrm{H}_{2} \mathrm{O}, 0.4 \mathrm{~g}$ $\mathrm{KH}_{2} \mathrm{PO}_{4}$, Murashige and Skoog basal salt micronutrients (Murashige and Skoog, 1962), $1 \mathrm{mg}$ thiamine hydrochloride, $0.2 \mathrm{mg}$ biotin, $0.1 \mathrm{mg}$ folic acid, $0.4 \mathrm{mg}$ nicotinic acid, $0.4 \mathrm{mg}$ pyridoxine $\mathrm{HCl}, 0.2 \mathrm{mg}$ choline $\mathrm{HCl}, 0.1 \mathrm{mg}$ riboflavin, $0.2 \mathrm{mg}$ Ca-panthothenic acid, $4 \mu \mathrm{g}$ cyanocobalmin, $0.1 \mathrm{mg}$ p-aminobenzoic acid, $100 \mathrm{mg}$ myo-inositol, $1.5 \mathrm{~g}$ proline, $0.5 \mathrm{~g}$ asparagine, $0.5 \mathrm{~g}$ glutamine. The medium was solidified with 10 g.L $\mathrm{L}^{-1}$ agar. After callus formation (after about 6 weeks) the sucrose concentration was reduced to $3 \%$. Then corn calli were maintained on Gamborg B5 medium (Gamborg et al., 1968).

For the preparation of cell suspensions, about $20 \mathrm{~g}$ callus cells were transferred to $200 \mathrm{ml}$ medium and incubated in the dark at $28{ }^{\circ} \mathrm{C}$, during which time they were kept constantly shaken. Callus-cultured cells and 
suspension cultures were transferred to fresh medium at intervals of 14 days.

For the studies of glufosinate-susceptibility and glufosinate-metabolism, cell suspensions containing $2 \mathrm{~g}$ cells $/ 20 \mathrm{ml}$ medium were incubated in shaken $100 \mathrm{ml}$ flasks in the dark at $28^{\circ} \mathrm{C}$. To prepare the glufosinatestock solutions a defined amount of glufosinate was dissolved in distilled water and filtered with sterile $0.2 \mu \mathrm{m}$ membrane filters. The concentrations used for susceptibility studies ranged from 0.05 to $10 \mathrm{mg} . \mathrm{L}^{-1}$ in non-transgenic and from 50 to $400 \mathrm{mg} . \mathrm{L}^{-1}$ in transgenic cell cultures. The metabolism studies were conducted with concentrations showing no significant growth retardation effects. The amount of radioactivity added to each culture was $0.01 \mathrm{MBq} \cdot \mathrm{ml}^{-1}$.

The influence of the herbicide on cell growth was analysed by determining the fresh weight of cells after an incubation period of 14 days. Within this period the fresh weights of untreated oilseed rape cells increased three times, that of untreated corn cells only 1.5 times.

The results presented are mean values derived from one final experiment with five parallel replicates each.

\section{Determination of ${ }^{14} \mathrm{CO}_{2}$}

During incubation of cell suspensions with ${ }^{14} \mathrm{C}$-labeled glufosinate, the flasks were closed with a small tube containing $10 \mathrm{~g}$ soda lime for absorption of released ${ }^{14} \mathrm{CO}_{2}$. The amount of ${ }^{14} \mathrm{CO}_{2}$ was analysed after treatment of soda lime with $50 \mathrm{ml}$ of $18 \% \mathrm{HCl}$, absorption of the ${ }^{14} \mathrm{CO}_{2}$ released in $25 \mathrm{ml} \mathrm{2-}$ aminoethanol/methanol (4/2, v/v) and measurement of a $1 \mathrm{ml}$ aliquot of this solution by liquid scintillation counting in $10 \mathrm{ml}$ scintillation cocktail (Rotiszint Eco Plus, Roth, Karlsruhe Germany).

\section{Extraction of glufosinate and its metabolites}

Cells were separated from the medium by filtration, and ground four times in a mortar with $7 \mathrm{ml}$ of a mixture of distilled water/methanol $(9 / 1, \mathrm{v} / \mathrm{v})$. The residues were separated from the extract after each extraction step by filtration. Culture media and cell extracts were freeze dried (Christ $\mathrm{GmbH}$, Osterode). The dry residues were dissolved in $1.5 \mathrm{ml}$ methanol/7.5 $\mathrm{mM} \mathrm{KH}_{2} \mathrm{PO}_{4}(1 / 1, \mathrm{v} / \mathrm{v})$, centrifuged at $10000 \mathrm{rpm}$ for 5 minutes and filtered using membrane filters $(0.45 \mu \mathrm{m}$, Roth, Karlsruhe $)$. Aliquots of $100 \mu \mathrm{l}$ were subjected to HPLC analysis.

The validation of the extraction and clean up procedure with reference compounds added to plant extracts showed that with exception of PPO all compounds tested remained stable during the clean up procedure. Contents of PPO decreased in some samples, with a simultaneous increase of glufosinate and MPP. This instability of PPO, resulting in glufosinate by enzymatic amination and MPP by spontaneous decarboxylation, is also described in the literature (Dröge-Laser et al., 1994).The mean overall recoveries of glufosinate and the metabolites MPP, MPB, MHB, MPA and $\mathrm{PPO}$ for the procedure in oilseed rape and corn cell cultures were between 86 and $90 \%$. For extraction of non-polar compounds, the residues were treated with $2 \times 7 \mathrm{ml}$ dichloromethane/methanol $(1 / 1, \mathrm{v} / \mathrm{v})$.

\section{Determination of radioactivity}

${ }^{14} \mathrm{C}$-Radioactivity of the extracts was measured with a liquid scintillation counter (Beckman type LS 8000, Geneve, Switzerland). To $10 \mathrm{ml}$ of scintillation cocktail (Rotiscint Eco Plus, Roth, Karlsruhe) $\leq 1 \mathrm{ml}$ of the extract was added. Unsoluble residues were oxidized using a biological oxidizer (Sample Oxidizer 307, Canberra Packard). Before combustion $200 \mu$ l combustaid (Canberra Packard GmbH, Dreieich, Germany) was added. The released ${ }^{14} \mathrm{CO}_{2}$ was absorbed and measured by scintillation counting in a mixture of $7 \mathrm{ml}$ Carbosorb $\mathrm{E}$ and $9 \mathrm{ml}$ Permafluor (Canberra Packard $\mathrm{GmbH}$, Dreieich, Germany). The radioactivity in the HPLC eluates was determined by a radiodetector (Radiomatic C505 TR, Canberra Packard GmbH, Dreieich) with a $500 \mu$ flow cell.

\section{High performance liquid chromatography (HPLC)}

HPLC was conducted using a Merck-Hitachi apparatus equipped with a pump (655 A 12), a UV-detector (L4200 UV/VIS), a radiodetector and an autosampler (L 7200). The separation of glufosinate and its metabolites was performed on a Nucleosil 100-5 SB ET 250/4 column (Macherey and Nagel, Düren) combined with a Spherisorb SAX precolumn $(5 \mu \mathrm{m}, 20 \mathrm{~mm} \times 4 \mathrm{~mm})$. The solvent systems used were $20 \mathrm{mM} \mathrm{KH}_{2} \mathrm{PO}_{4}(\mathrm{pH} \mathrm{1.95)/}$ methanol $(9 / 1, \mathrm{v} / \mathrm{v})$ (system 1) and $7.5 \mathrm{mM} \mathrm{KH}_{2} \mathrm{PO}_{4}(\mathrm{pH}$ $1.95) /$ methanol $(3 / 7, \mathrm{v} / \mathrm{v})$ (system 2$)$. Identification of glufosinate and its metabolites was carried out by cochromatography with standard substances in the two different chromatographic systems. Retention times (minutes) for glufosinate and its metabolites were as follows: 3.9 (GA), 6.6 (MPB), 7.8 (MPP), 7.1 (MHB), 11.8 (NGA), 14 (MPA) and 45 (PPO) in system 1, and 
16 (GA), 14 (MPB), 20 (MPP), 26 (MHB), 29 (NGA), 45 (MPA) and 120 (PPO) in system 2.

Solvent system 1 was suitable for the detection of PPO. Solvent system 2 was used for separating the other metabolites. The metabolites were identified in these chromatographic systems by cochromatography with authentic reference compounds, each of which had different effects on chromatography. Since solvent 1 contains a higher concentration of $\mathrm{KH}_{2} \mathrm{PO}_{4}$ the anionic exchange effects were dominant in this system, whilst in solvent 2 the high content of methanol and the lower ionic strength had a stronger influence on distribution effects during chromatography.

\section{ACKNOWLEDGEMENTS}

The present study was financially supported by the Bundesministerium für Bildung, Wissenschaft, Forschung und Technologie (Project No. 0311291). The authors are responsible for the contents. We thank Dr. A. Zumdick and Aventis CropScience $\mathrm{GmbH}$ for helpful discussions and for kindly providing ${ }^{14} \mathrm{C}$-glufosinate enantiomers as well as the ${ }^{14} \mathrm{C}$-labeled reference compounds. The excellent technical assistance of Mrs. B. Wohner is gratefully acknowledged.

Received April 21, 2001; accepted December 4, 2001.

\section{REFERENCES}

Behrendt H, Matthies M, Gildemeister H, Görlitz G (1990) Leaching and transformation of glufosinate-ammonium and its main metabolite in a layered column. Environ. Toxicol. Chem. 9: 541-549

Dröge W, Broer I, Pühler A (1992) Transgenic plants containing the phosphinothricin- $\mathrm{N}$-acetyltransferase gene metabolize the herbicide L-phosphinothricin (glufosinate) differently from untransformed plants. Planta 187: 142-151

Dröge-Laser W, Siemeling U, Pühler A, Broer I (1994) The metabolites of the herbicide L-phosphinothricin (glufosinate) - identification, stability, and mobility in transgenic, herbicide-resistant, and untransformed plants. Plant Physiol. 105: $159-166$

Gamborg OL, Miller RA, Ojima K (1968) Nutrient requirements of suspension cultures of soybean root cells. Exp. Cell Res. 50: 151-158

Jansen C, Schuphan I, Schmidt B (2000) Glufosinate metabolism in excised shoots and leaves of twenty plant species. Weed Science 48: 319-326

Komoßa D, Sandermann H jr (1992) Plant metabolism of herbicides with C-P Bonds: phosphinothricin. Pestic. Biochem. Physiol. 43: 95-102

Langebartels C, Harms H (1986) Plant cell suspension cultures as test systems for an ecotoxicological evaluation of chemicals. Angew. Botanik 60: 113-123

Lea PJ, Joy KW, Ramos JL, Guerrero MG (1984) The action of the 2-amino-4-(methylphosphinyl)-butanoic acid (phosphinothricin) and its 2-oxo-derivative on the metabolism of cyanobacteria and higher plants. Phytochemistry 23: 1-6

Leason M, Cunliffe D, Parkin D, Lea PJ, Miflin B (1982) Inhibition of pea leaf glutamine synthetase by methioninsulfoximine. Phosphinothricin and other glutamate analogs. J. Phytochem. 21: 855-857

Müller B, Schuphan I, Schmidt B (1999) Metabolismus von Glufosinate in Zellkulturen verschiedener Pflanzenspezies (transgen, nicht-transgen) - Probleme bei Versuchsdesign, Aufarbeitung und Analytik, Mitteilungen der Deutschen Phytomedizinischen Gesellschaft 29: 12-13

Müller B, Zumdick A, Schuphan I, Schmidt B (2001) Metabolism of the herbicide glufosinate-ammonium in plant cell cultures of transgenic (rhizomania-resistant) and nontransgenic sugar beet (Beta vulgaris), carrot (Daucus carota), purple foxglove (Digitalis purpurea) and thorn apple (Datura stramonium). Pest Manag. Sci. 57: 46-56

Murashige T, Skoog F (1962) A revised medium for rapid growth and bioassay with tobacco tissue cultures. Physiol. Plant. 15: 473-477

Wohlleben W, Arnold W, Broer I, Hillemann D, Strauch E, Pühler A (1988) Nucleotide sequence of the phosphinothricin- $N$-acetyl-transferase gene from Streptomyces viridochromogenes Tü 494 and its expression in Nicotiana tabacum. Gene 70: 25-37

Zumdick A, Goerlitz G, Erzgräber B, Stumpf K, Dorn E (1998) Glufosinate-ammonium and N-acetyl-glufosinate: Soil metabolism. 9th Int. Congress of Pesticide Chemistry, London 
